\title{
Rescuing the Zygote Argument
}

\section{Gabriel De Marco}

\begin{abstract}
In a recent paper, Kristin Mickelson argues that Alfred Mele’s Zygote Argument, a popular argument for the claim that the truth of determinism would preclude free action or moral responsibility, is not valid. This sort of objection is meant to generalize to various manipulation arguments. According to Mickelson, the only way to make such arguments valid is to supplement them with an argument that is an inference to the best explanation. In this paper, I argue that there are two other ways in which the proponent of such manipulation arguments can modify their argument, neither of which requires an inference to the best explanation. I then briefly consider and respond to a worry with one of these proposed solutions.
\end{abstract}

\section{The Zygote Argument is Invalid}

Alfred Mele’s Zygote Argument begins with a case. Diana, a goddess with special powers and knowledge, wants event $E$ to occur 30 years after time $t$. Diana knows what the state of the universe is just before $t$ and she knows the laws of nature of her deterministic universe. With these things in mind, she creates a zygote, $Z$, in Mary at time $t$ which will develop into Ernie. Diana does this knowing that, given the state of the world and the laws, Ernie will, 30 years in the future, perform action $A$ which will bring about event $E$. When Ernie performs $A$, he does so while fulfilling standard compatibilist sufficient conditions for free action. The Zygote Argument proceeds as follows:

P1. Because of the way his zygote was produced in his deterministic universe, Ernie is not a free agent and is not morally responsible for anything.

P2. Concerning free action and moral responsibility of the beings into whom zygotes develop, there is no significant difference between the way Ernie's zygote comes to exist and the way any normal human zygote comes to exist in a deterministic universe.

C. So determinism precludes free action and moral responsibility (2006: 189). 
In a recent paper, Kristin Mickelson (2015b) argues that this argument is invalid. Although she grants that the premises of the Zygote Argument entail that there aren't free or responsible agents in a deterministic universe, Mickelson argues that this is not sufficient for the conclusion. The conclusion of the argument - that determinism precludes or undermines free action or moral responsibility - requires further argumentation; for, although there may be no free or responsible agents in deterministic worlds, it might not be the truth of determinism that explains this. ${ }^{1}$ Mickelson does an admirable job of parsing through the different versions of the Zygote Argument and arguing that the premises are not to be read as providing much support for this further explanatory thesis.

\section{Terms and an Initial Solution}

Mickelson introduces some terms in order to help keep track of the issue with manipulation arguments. ${ }^{2}$ According to Mickelson, the term “incompatibilism” is to refer to the "positive, explanatory view that necessarily, anyone who is subject to deterministic laws is unfree (at least in part) because or in virtue of being subject to such laws” (2015b: 9). "Incompossibilism,” on the other hand, names “the negative, non-explanatory view that deterministic laws and free action are incompossible” (2015b: 9). For the purposes of this paper, I will read “incompossibilism” as being the negative, non-explanatory view that necessarily, it is not the case that "deterministic laws obtain and someone who is subject to the laws performs a free action” (2015b: 9, fn. 10). ${ }^{3}$ The

\footnotetext{
${ }^{1}$ Some might think that the "because" clause in 1 is meant to do some of this work. Mickelson makes two points in response: 1) newer versions of the Zygote Argument have dropped the "because" clause altogether, 2) the "because" clause seems to be "meant to point us in the general direction of (what seems to be) the source of Ernie's problems, but does not positively identify deterministic causation as menacing" (2015b: 4).

${ }^{2}$ This classification of positions is also offered in Mickelson (2015a).

${ }^{3}$ The change is made here for ease of presentation. Mickelson states that on her characterization of the views, incompatibilism entails incompossibilism (9), although in a footnote she recognizes that it only entails a qualified version of incompossibilism. This qualified version of incompossibilism is how I am reading "incompossibilism" here. For the purposes of this paper and hers, the difference is not significant. The shift to agents who are subject
} 
truth of incompatibilism would entail the truth of incompossibilism, but not vice versa, since incompatibilism also posits a further explanatory thesis. "Compatibilism” is then to be understood as the negation of the incompatibilist thesis, and "compossibilism" is then to be taken as the negation of the incompossibilist thesis.

As Mickelson points out, the Zygote Argument concludes with the incompatibilist thesis, yet the premises only entail the incompossibilist thesis, thereby making it an invalid argument. This issue is present in quite a few manipulation arguments. The standard form of manipulation arguments is similar to what we see in the Zygote Argument: one premise states that an agent in a deterministic universe who has been manipulated does not act freely or responsibly, and a second premise states that there is no significant difference, with regards to free action or moral responsibility, between the manipulated agent and a standard agent who fulfills compatibilist conditions in a deterministic universe. Manipulation arguments often conclude with incompatibilism rather than incompossibilism, and consequently are flawed in the same way that the Zygote Argument is. ${ }^{4}$

Before showing how proponents of such arguments should respond, it will be helpful to fix an issue with this classification of positions. Since, on Mickelson's classification, “incompatibilism” and "incompossibilism” refer to different theses, the terms which refer to their

\footnotetext{
to deterministic laws is meant to allow for the possibility that there is an agent in a deterministic universe who is not subject to the laws. It is important to note that if an argument proves the unqualified incompossibilist thesis, then it will prove the qualified version as well.

${ }^{4}$ Some might reject the claim that these arguments are flawed in this way. One might think that the conclusion of say, the Zygote Argument, although it uses the word "preclude," is really just signaling what Mickelson calls incompossibilism. That is, one might think that if it is true that "necessarily, if an agent is subject to deterministic laws, then they do not act freely or responsibly" (a claim which is entailed by a statement of incompossibilism), then it is true that being subject to deterministic laws precludes free action or moral responsibility. If this is right, then proving incompossibilism is sufficient to prove the conclusion of the Zygote Argument.
} 
negations - “compatibilism” and “compossibilism” respectively - will refer to different theses as well. Such a distinction between the compatibilist and compossibilist theses is mistaken.

We can begin with considering “compatibilism” by itself, which is to be taken as referring to the negation of "incompatibilism." The incompatibilist thesis is a conjunction of two separate theses:

D. Necessarily, anyone who is subject to deterministic laws is unfree.

E. D is true because these agents are subject to deterministic laws.

$\mathrm{D}$ is the incompossibilist thesis and $\mathrm{E}$ is the further explanatory thesis offered by the incompatibilist. If compatibilism is meant to be the negation of the conjunction of $\mathrm{D}$ and $\mathrm{E}$, then someone who rejects just one of either D or E will be a compatibilist. But consider impossibilism; the view that necessarily, there are no free or responsible agents. One might be an impossibilist without thinking that determinism itself undermines free action. ${ }^{5}$ That is, one might think that a certain necessary condition on free action, $C$, cannot be instantiated. If one holds this position, then one might hold $\mathrm{D}$ while rejecting $\mathrm{E}$, for $C$ fails to obtain in any world, regardless of whether the world is a deterministic one. This sort of theorist would accept incompossibilism, but not incompatibilism. On the definition of "compatibilism” that Mickelson gives us, someone with this view would be a compatibilist. A possible position, on this use of the terms, is a compatibilist impossibilism. This would be quite a different use of the term than what one normally finds in the free will literature. On this reading, “compatibilism” does not refer to a thesis about the compatibility of anything, since a statement of the negation of incompatibilism does not entail a statement of the negation of incompossibilism.

\footnotetext{
${ }^{5}$ As I show in section 4, although this is a possible position, an impossibilist need not reject incompatibilism.
} 
As the term is standardly used, “compatibilism” refers to a thesis about the compatibility of being subject to deterministic laws, and acting freely or responsibly: a thesis that these things are compatible. Holding this view requires a rejection of not just one of the conjuncts that make up the incompatibilist thesis, but rather both. I suggest that we take "compatibilism” and “compossibilism” to refer to the same thesis: the negation of incompossibilism. Proving either incompatibilism or incompossibilism would be sufficient to prove that compatibilism is false.

The dialectical role of the Zygote Argument, and manipulation arguments more generally, has been to prove that compatibilism is false; these are usually employed as arguments against the compatibilist. ${ }^{6}$ Whether these arguments prove incompatibilism or incompossibilism is not very important for the debate, since proving either one of them would prove the negation of compatibilism. For those manipulation arguments that are invalid for the reasons that Mickelson gives, as well as for the Zygote Argument, an easy fix would be to change their conclusion to the claim that compatibilism is false. Implementing this strategy would allow the arguments to retain their dialectical role without having to fuss over the difference between incompatibilism and incompossibilism.

\section{A Different Solution}

Suppose, instead, that someone wishes to provide a manipulation argument with incompatibilism as its conclusion. In order to make such an argument valid, we could add what Mickelson calls a diagnostic premise. This would make the form of such manipulation arguments as follows:

\footnotetext{
${ }^{6}$ There are some exceptions, namely, in debates about whether free action or moral responsibility should have a historical condition. In these debates, manipulation cases are often appealed to, since adding this historical condition is one of the compatibilist strategies for responding to certain manipulation arguments.
} 
1. Victim Premise: Due to some feature of the (apparent) manipulation scenario, the (apparent) manipulation victim $S$ is not free or responsible for performing an action $A$.

2. Diagnostic Premise: The menacing feature of the (apparent) manipulation scenario - the feature that accounts for $S$ 's lack of freedom and responsibility - is F.

3. Same-Feature Premise: $F$ is present in both the (apparent) manipulation scenario and any normal determination scenario.

4. Conclusion: No one is free or responsible in any normal determination scenario in virtue of $F$ (2015b: 10).

Given the newly added diagnostic premise, we now have an argument that can pick out determinism (or a feature of it) as the feature that undermines free action and moral responsibility in deterministic worlds. Since we would be picking out determinism, or a feature of it, as the menacing feature, we would be able to support the explanatory claim required for a statement of incompatibilism.

According to Mickelson, a defense of the diagnostic premise of this argument requires an argument to the best explanation for the claim that the truth of determinism is the best explanation for S's lack of freedom in this case. This is because, as she sees it, there is no viable alternative to defending the diagnostic premise (2015b: 11). However, there is a different way to make such arguments valid.

As we've seen, the issue with manipulation arguments for incompatibilism that don't involve a diagnostic premise is that one could hold incompossibilism while rejecting incompatibilism. One might think that free or responsible actions are impossible to perform, in which case it need not be something about determinism (or being subject to deterministic laws) that explains why agents who are subject to deterministic laws do not act freely or responsibly. If this view were true, then the diagnostic premise would be false. To put things differently, consider the following three claims: 
D. Necessarily, anyone who is subject to deterministic laws is unfree.

E. D is true because these agents are subject to deterministic laws.

N. Necessarily, no agent acts freely or responsibly.

$\mathrm{D}$ is a statement of incompossibilism, and is entailed by the premises of the Zygote Argument. E is the further claim that the proponent of the Zygote Argument, or manipulation arguments in general, would have to prove in order to conclude that incompatibilism is true. The conjunction of $\mathrm{D}$ and $\mathrm{E}$ is a statement of incompatibilism. What Mickelson points out is that $\mathrm{D}$ may not be sufficient for $\mathrm{E}$ if $\mathrm{N}$ is true.

$\mathrm{D}, \mathrm{E}$ and $\mathrm{N}$ form a consistent trio, since the truth of $\mathrm{N}$ may be due in part to the fact that determinism precludes free will or moral responsibility. The threat to standard manipulation arguments for incompatibilism comes from the possibility of the conjunction of D, not-E and N, which also forms a consistent trio. Consider again the impossibilist who holds $\mathrm{N}$ because, on their view, a certain necessary condition on free action, $C$, cannot be instantiated. This sort of impossibilist position is consistent with $\mathrm{D}$, not-E and $\mathrm{N}$. Because of the consistency of this trio, an inference from $\mathrm{D}$ to $\mathrm{E}$ is problematic. ${ }^{7}$

What I suggest is that the proponent of a manipulation argument adds the following premise:

P3. Possibly, an agent acts freely or responsibly.

\footnotetext{
${ }^{7}$ I would like to thank an anonymous referee for suggesting that I clarify this point.
} 
P3 is a negation of $\mathrm{N}$; by positing $\mathrm{P}$, the proponent of the argument avoids the threat to the inference from $\mathrm{D}$ to $\mathrm{E}$. This threat arose from the consistency of D, not-E and N; but by removing $\mathrm{N}$ from the mix, the proponent can now make the inference from $\mathrm{D}$ to $\mathrm{E}$.

Suppose that D and P3 are true, and that there is a possible world where agents are subject to deterministic laws. ${ }^{8}$ If we have two things that are possible - an agent's being subject to deterministic laws and an agent's acting freely or responsibly - but they are not compossible (D), then there must be something about these two things that explains why they are not compossible. That is, there must be some feature of these two things that prevents them from being coinstantiated. If there are no possible agents who are subject to deterministic laws that act freely or responsibly, but there are possible agents who act freely or responsibly, then there must be something that comes along with an agent's being subject to deterministic laws which explains why such agents do not act freely or responsibly; being subject to deterministic laws would preclude free or responsible action. But this is all that we needed to justify E.

Notice that nothing of what I have said above amounts to an inference to the best explanation. Adding P3 to the Zygote Argument, or to manipulation arguments for incompatibilism, would not thereby make it a best explanation argument, nor would it need to be supplemented by one. ${ }^{9}$ This gives us reason to reject Mickelson's thesis that such arguments need to be supplemented with an inference to the best explanation in order to be valid.

\footnotetext{
${ }^{8}$ This last supposition is one that is fairly uncontroversial, so I will not argue for it here.

${ }^{9}$ It is quite possible that there is a hidden premise of this sort in the Zygote Argument when it is presented in Free Will and Luck. In the first chapter of the book, Mele voices his continued belief in agnostic autonomism, a view which is agnostic about the truth of compatibilism, but holds that there are free and responsible human beings 2006: pp 4-5). Since agnostic autonomism holds that there are free and responsible agents, its truth would entail that "Possibly, an agent acts freely or responsibly." If we take P3 to be an implicit premise of the Zygote Argument, then it does turn out to be valid, at least when it is presented in the context of Free Will and Luck.
} 


\section{A Worry}

One might worry about the solution just proposed: by adding P3, we make the argument weaker. This adds a further claim that the proponent must rely on and it opens up a further avenue for the opponent to provide an objection. If one rejects P3, then one can avoid this sort of argument for incompatibilism.

This worry is misplaced. One opponent to this sort of argument would be the compatibilist, who rejects the incompossiblist thesis. Notice that this sort of opponent cannot reject P3 while maintaining compatibilism. By rejecting P3, this opponent would be denying the possibility of an agent who acts freely or responsibly. If there are no possible agents who act freely or responsibly, then there are no possible agents who are subject to deterministic laws that act freely or responsibly. This would then force the opponent to reject compatibilism.

Another sort of opponent to this argument would be the impossibilist, someone who holds that P3 is false. For some impossibilists a manipulation argument supplemented with a bestexplanation argument for the diagnostic premise will fare no better, for they already have what they take to be the explanation of the claim that no agent acts freely or responsibly, and this explanation does not involve determinism.

There are, however, two sorts of impossibilists who may oppose this variation of the manipulation argument. Suppose that one thinks that there are at least two necessary conditions on free action or moral responsibility, $C 1$ and $C 2$. Further suppose that, although $C 1$ is impossible to achieve, C2 can be achieved, but only in worlds which are not deterministic. This sort of impossibilist may believe that being subject to deterministic laws precludes free action or moral responsibility by precluding one of its conditions. On this view there would be two explanations 
for why any possible agent who is subject to deterministic laws does not act freely or responsibly. Alternatively, one may be an impossibilist who thinks that there are at least two necessary conditions on free action or moral responsibility, $C 3$ and $C 4$, that there are possible agents who fulfill $C 3$, that there are possible agents that fulfill $C 4$, but that there are no possible agents who fulfill both $C 3$ and $C 4$. This sort of impossibilist might think that determinism precludes $C 3$ but that in order to fulfill $C 4$, an agent must be subject to deterministic laws. On this view, an agent's being subject to deterministic laws would be the only explanation for why an agent who is subject to such laws does not act freely or responsibly (provided that she fulfills C4).

Both of these sorts of impossibilists would reject P3, yet they might still be incompatibilists. A manipulation argument supplemented with a best-explanation argument for the diagnostic premise may fare better against these sorts of impossibilists than my version does. But this is not a problem: one can consistently offer a manipulation argument which includes P3 while also offering one that is supplemented by a best-explanation argument. I am not here suggesting that supplementing manipulation arguments with an inference to the best explanation is problematic. Rather, I am simply arguing that, contrary to Mickelson's claim, this is not the only way to make a manipulation argument for incompatibilism valid.

\section{Conclusion}

In this paper I have offered two ways to make the Zygote Argument, and manipulation arguments for incompatibilism, valid. One solution involves changing the conclusion to the claim that compatibilism is false. The second solution involves adding the premise that possibly, an agent acts freely or responsibly. One weakness of adding this premise to the argument is that this premise will be rejected by an impossibilist. A strength of adding this premise is that it avoids the complications that arise in attempting to argue that an agent's being subject to deterministic laws 
is the best explanation for why such agents do not act freely or responsibly. ${ }^{10}$ Furthermore, neither of these solutions require the use of an inference to the best explanation.

\section{References}

Mele, A. (2005). “A Critique of Pereboom’s ‘Four-Case Argument’ for Incompatibilism,” Analysis 65: 75-80.

Mele, A. (2006). Free Will and Luck. New York: Oxford University Press.

Mickelson, K. (2015a). “A Critique of Vihvelin’s Three-fold Classification,” Canadian Journal of Philosophy 45: 85-99.

Mickelson, K. (2015b). “The Zygote Argument is invalid: Now what?” Philosophical Studies: Online

Pereboom, D. (2014). Free Will, Agency, and Meaning in Life. New York: Oxford University Press.

${ }^{10}$ Derk Pereboom (2014) attempts to offer a manipulation argument that is an inference to the best explanation. Some complications that arise from such an argument are pointed out by Mele $(2005,2006)$. 